\title{
Occurrence of Riboflavinyl Glucoside in Rat Urine
}

\author{
Hiroshi OHKawa, Nobuko OHISHI, and Kunio YAGI ${ }^{1}$ \\ Institute of Biochemistry, Faculty of Medicine, \\ University of Nagoya, Nagoya 466, Japan
}

(Received February 15, 1983)

\begin{abstract}
Summary To investigate the metabolism of riboflavin, $\left[2-{ }^{14} \mathrm{C}\right]-$ riboflavin was administered orally to a rat. The urine pooled for $24 \mathrm{~h}$ after administration was fractionated by paper and silica gel thin layer chromatographies using various solvent systems. Among the radioactive metabolites, riboflavinyl glucoside was found along with 7-carboxy lumichrome and 8-carboxy lumichrome. The radioactivity of riboflavinyl glucoside comprised about $6 \%$ of the total radioactivity excreted in the urine during $24 \mathrm{~h}$.
\end{abstract}

Key Words riboflavin, riboflavinyl glucoside

In our previous paper(1), we reported on the occurrence of two new metabolites of riboflavin in rat urine after oral administration of radioactive riboflavin and determined their structures to be 7-carboxy lumichrome and 8carboxy lumichrome. They comprised $46.0 \%$ of the total radioactivity excreted into the urine, but still $22.7 \%$ of the total radioactivity was ascribed to unknown metabolites of riboflavin. We examined further the unknown metabolites, and found the occurrence of riboflavinyl glucoside. In this paper, the separation and identification of riboflavinyl glucoside in rat urine are reported.

\section{MATERIALS AND METHODS}

Materials. $\left[2-{ }^{14} \mathrm{C}\right] \mathrm{Riboflavin}$ (specific radioactivity, $32 \mathrm{mCi} / \mathrm{mmol}$ ) was purchased from the Radiochemical Centre, Amersham, and purified by paper chromatography with the solvent mixture of $n$-butanol-glacial acetic acid-water $(4: 1: 5$, $\mathrm{v} / \mathrm{v}$, upper phase). Its purity was checked by silica gel thin layer chromatography (TLC) according to Yagi and Ohishi (2).

$\alpha$-Glucosidase (from yeast, $50 \mathrm{U} / \mathrm{mg}$ protein) was obtained from Boehringer, Mannheim, $\beta$-glucosidase (from almonds, $7.2 \mathrm{U} / \mathrm{mg}$ solid) from Sigma Chemical Co., St. Louis, and the scintillation cocktail (Scintisol-500) from Wako Pure Chemical Industries Ltd., Osaka.

Riboflavinyl glucoside was prepared, according to the method of Whitby (3),

1 大川 博, 大石誠子, 八木國夫 
by the incubation of riboflavin with the enzyme from the acetone powder of rat liver homogenate.

Paper (Toyo No. 50) used for chromatography was purchased from Toyo Kagaku Sangyo Co., Ltd., Tokyo, TLC plates of silica gel (Kiesel gel 60) and cellulose from E. Merck, Darmstadt, and diethylaminoethyl cellulose (DE-32) from Whatman Ltd., Springfield, Kent. All other chemicals used were of reagent grade of purity.

Solvent systems used for chromatography are as follows: $\mathrm{S}_{1}, n$-butanol-glacial acetic acid-water $(4: 1: 5, \mathrm{v} / \mathrm{v}$, upper phase $) ; \mathrm{S}_{2}$, benzene- $n$-butanol-methanol-water ( $1: 2: 1: 1, \mathrm{v} / \mathrm{v}$, upper phase).

Animals. Male Wistar rats weighing $140-160 \mathrm{~g}$ were used and fed a standard laboratory chow (Nihon Clea CE-2) obtained from Nihon Clea, Tokyo. $\left[2-{ }^{14} \mathrm{C}\right]-$ Riboflavin was dissolved in $0.5 \%$ sodium carboxymethyl cellulose solution and administered orally at a dose of $37.3 \mu \mathrm{g}\left(4.684 \times 10^{6} \mathrm{dpm}\right)$ per rat, which was placed in a metabolic cage to separate urine from faeces. The urine was collected for $24 \mathrm{~h}$ after administration in a brownish flask containing two drops of toluene and $0.2 \mathrm{ml}$ of glacial acetic acid to prevent bacterial growth, and stored at $-20^{\circ} \mathrm{C}$ until use.

In order to obtain a large amount of metabolites from rat urine, nonradioactive riboflavin was administered in a similar manner as above.

Analytical procedure. The radioactivity was measured in a Beckman liquid scintillation counter model LS335 by use of Scintisol-500. The radiochromatogram of paper or silica gel TLC plate was obtained with an Aloka radiochromatogram Scanner model TRM-18. Flavin concentration was determined by the lumiflavin fluorescence method (4). Absorption and fluorescence spectra were measured in a Union Giken spectrophotometer SM-401 and a Shimadzu spectrofluorophotometer RF502, respectively.

Hydrolysis of the sample with $\mathrm{HCl}$ was done as follows; the mixture of equal volumes $(0.2 \mathrm{ml}$, each) of the aqueous solution of the sample and $4 \mathrm{~N} \mathrm{HCl}$ was

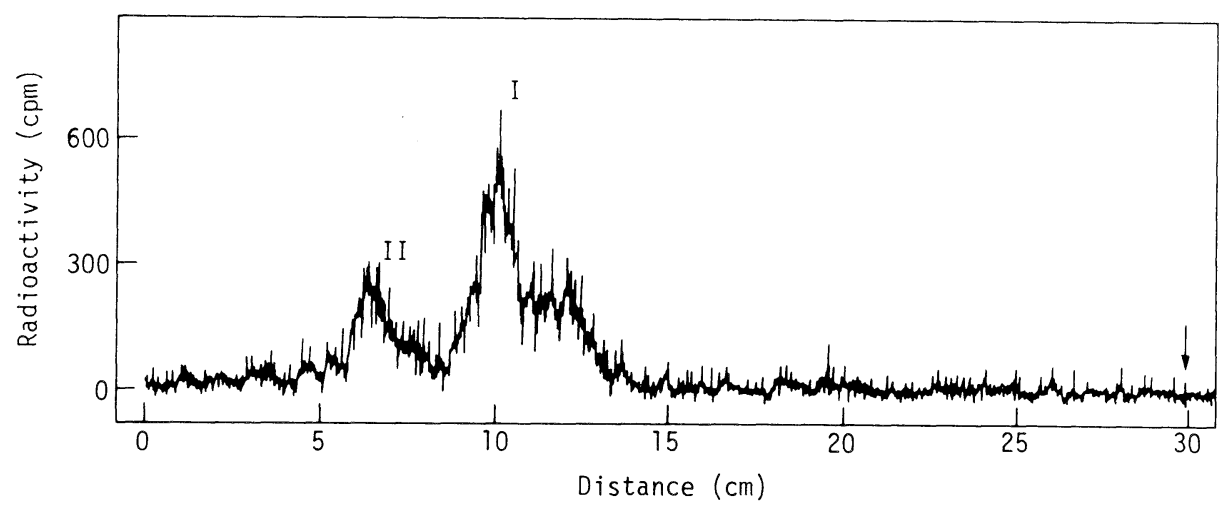

Fig. 1. A typical radiochromatogram of flavins in rat urine after administration of [2${ }^{14}$ C]riboflavin. Details, see text. Solvent for paper chromatography: $n$-butanolglacial acetic acid-water (4:1:5, v/v, upper phase). Arrow shows solvent front $(30 \mathrm{~cm})$. 
heated at $100^{\circ} \mathrm{C}$ in a sealed tube for $2 \mathrm{~h}$ in the dark. After hydrolysis, the mixture was dried up with a rotatory evaporator and dissolved in a minimum volume of distilled water. For enzymatic hydrolysis with glucosidase, the reaction mixture containing $50 \mu \mathrm{l}$ of an aqueous solution of the sample, $50 \mu \mathrm{l}$ of glucosidase $(\alpha-$, $250 \mathrm{U} / \mathrm{ml} ; \beta-, 144 \mathrm{U} / \mathrm{ml}$ ) and $50 \mu \mathrm{l}$ of $0.2 \mathrm{M}$ acetate buffer was incubated at $37^{\circ} \mathrm{C}$ for $4 \mathrm{~h}$. The $\mathrm{pH}$ of the buffer was 6.0 for $\alpha$-glucosidase and 4.5 for $\beta$-glucosidase. After hydrolysis, the mixture was dried with a rotatory evaporator and dissolved in a small volume of distilled water.

Oxidation of the sample with periodic acid was carried out as follows; an aqueous solution of the sample was mixed with an equal volume of $0.03 \mathrm{M}$ periodic acid and the mixture was stood for about $12 \mathrm{~h}$ at room temperature in the dark.

\section{RESULTS}

\section{Separation and purification of a metabolite of riboflavin}

The pooled urine $(c a .20 \mathrm{ml})$ of rat administered with $\left[2-{ }^{14} \mathrm{C}\right]$ riboflavin was made acidic with an equal volume of $1 \%$ acetic acid and extracted 2 times with an equal volume of water-saturated chloroform in order to separate chloroformsoluble compounds. The water phase was saturated with ammonium sulfate and flavins were extracted with phenol. Flavins in phenol were extracted with about $5 \mathrm{ml}$ of distilled water after the addition of ethyl ether as described elsewhere (5). The solution containing flavins was subjected to paper chromatography with solvent $S_{1}$. A typical radiochromatogram is shown in Fig. 1. Two major radioactive peaks, I $\left(R_{f}\right.$ $0.30-0.45)$ and II $\left(R_{f} 0.22\right)$, were found and they exhibited a greenish yellow

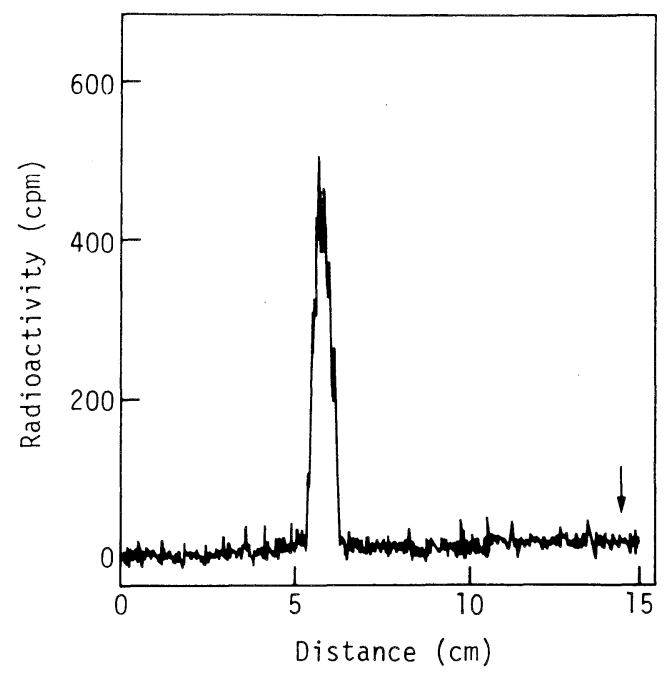

Fig. 2. Radiochromatogram of the purified metabolite. Solvent for silica gel TLC: benzene- $n$-butanol-methanol-water $(1: 2: 1: 1, \mathrm{v} / \mathrm{v}$, upper phase). Arrow shows solvent front $(14.4 \mathrm{~cm})$. 
fluorescence under illumination at $365 \mathrm{~nm}$. Riboflavin and two metabolites of flavin, 8-carboxy lumichrome and 7-carboxy lumichrome, were included in peak I(1).

The fraction of $R_{f}$ value at 0.22 (peak II in Fig. 1) on the paper chromatogram was cut out and eluted with solvent $\mathrm{A}$ (methanol- $3 \%$ acetic acid, $2: 8, \mathrm{v} / \mathrm{v}$ ). The eluate concentrated with a rotatory evaporator was subjected to the first silica gel TLC developed with solvent $\mathrm{S}_{1}$. A main radioactive band $\left(R_{f} 0.23\right)$ was scraped off and the metabolite was extracted two times with hot solvent $\mathrm{A}$. The extract was concentrated with a rotatory evaporator at $40^{\circ} \mathrm{C}$, dissolved in a minimum volume of solvent $\mathrm{A}$, and applied to the second TLC developed with solvent $\mathrm{S}_{2}\left(R_{f} 0.40\right)$. A single radioactive spot was observed on the TLC plate as shown in Fig. 2, and was found to be homogeneous as far as checked by its fluorescence and by the charring spot with $50 \% \mathrm{H}_{2} \mathrm{SO}_{4}$.

In the case of the administration of non-radioactive riboflavin, flavins in about $1,000 \mathrm{ml}$ of pooled rat urine were extracted with phenol after the chloroform treatment and transferred to about $200 \mathrm{ml}$ of distilled water by adding ethyl ether in the same manner as radioactive riboflavin. Flavins were first charged on DE-32 column $(3.0 \times 20 \mathrm{~cm})$ packed with distilled water, and eluted with about $500 \mathrm{ml}$ of distilled water. The eluate was dried with a rotatory evaporator and dissolved in about $20 \mathrm{ml}$ of solvent $\mathrm{A}$. This solution contained the metabolite of riboflavin under investigation. Further purification of this metabolite was carried out by following the procedure from the first paper chromatography to the second silica gel TLC for the purification of radioactive metabolite described above. The eluate from the second silica gel TLC plate was dried, dissolved in a minimum volume of solvent mixture of pyridine-glacial acetic acid-water $(5: 1: 3, \mathrm{v} / \mathrm{v})$, and stood overnight after addition of 5 volumes of acetone to remove the contaminating silica gel. Precipitated silica gel was removed by centrifugation. After evaporation of the solvent, the residue was dissolved in a small volume of solvent $\mathrm{A}$ and finally subjected to paper chromatography with solvent $S_{2}\left(R_{f} 0.17\right)$. The metabolite was

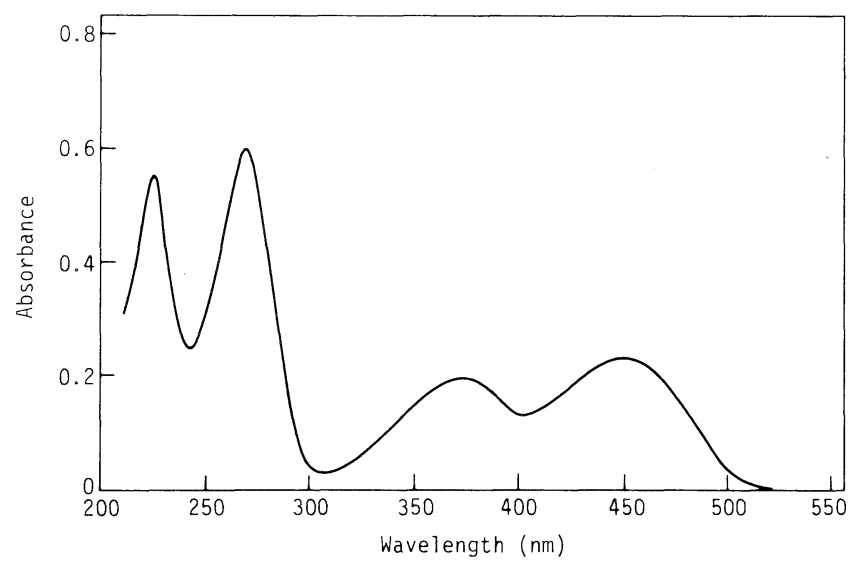

Fig. 3. Absorption spectrum of the metabolite in distilled water. 
extracted with distilled water.

\section{Determination of the structure of the metabolite}

The ultraviolet and visible absorption spectrum of the metabolite in distilled water is shown in Fig. 3. The maximum absorption was found at 220, 266, 373 and $445 \mathrm{~nm}$. The spectrum was similar to that of riboflavin or riboflavinyl glucoside in the region from $210 \mathrm{~nm}$ to $500 \mathrm{~nm}$. The ratios of absorbance of the metabolite, $A_{260} / A_{450}, A_{260} / A_{375}$ and $A_{375} / A_{450}$ were $2.26,2.65$ and 0.85 , respectively. By the addition of dithionite, the spectrum of this compound turned to the reduced one, which was reversed to the oxidized one with air. In addition, it exhibited a greenish yellow fluorescence; the maximum emission was found at $540 \mathrm{~nm}$ with excitation at $450 \mathrm{~nm}$. From these spectroscopic properties, it is considered that the metabolite possesses a structure like riboflavin.

The $R_{f}$ values of the metabolite on silica gel TLC developed with several solvent systems are shown in Table 1. It is clear that the $R_{f}$ values of the metabolite are different from those of riboflavin, FMN and lumiflavin, but coincide with those of riboflavinyl glucoside with all solvent systems used.

Table $1 . \quad R_{f}$ values of the metabolite on silica gel TLC.

\begin{tabular}{lcccc}
\hline & I & II & III & IV \\
\hline Metabolite & 0.23 & 0.40 & 0.12 & 0.41 \\
Riboflavin & 0.36 & 0.52 & 0.30 & 0.34 \\
FMN & 0.15 & 0.23 & 0.01 & 0.49 \\
Riboflavinyl glucoside & 0.23 & 0.40 & 0.12 & 0.41 \\
Lumiflavin & 0.42 & 0.58 & 0.48 & 0.12 \\
\hline
\end{tabular}

Compounds were detected by their yellow fluorescence with excitation at $365 \mathrm{~nm}$. Solvent systems: I, $n$-butanol-glacial acetic acid-water ( $4: 1: 5, \mathrm{v} / \mathrm{v}$, upper phase); II, benzene- $n$-butanol-methanol-water $(1: 2: 1: 1, \mathrm{v} / \mathrm{v}$, upper phase); III, methyl ethyl ketone-isoamyl alcohol-glacial acetic acid-water $(40: 40: 7: 13, \mathrm{v} / \mathrm{v}) ; \mathrm{IV}, 5 \% \mathrm{Na}_{2} \mathrm{HPO}_{4}$.

The hydrolysis of the metabolite with $2 \mathrm{~N} \mathrm{HCl}$ at $100^{\circ} \mathrm{C}$ produced riboflavin as in the case of riboflavinyl glucoside (Table 2). The product of the photolysis of the metabolite in alkaline medium was identified as lumiflavin by its migration on silica gel TLC (Tables 1 and 2). From the facts mentioned above, we expected that the metabolite is an ester of riboflavin like riboflavinyl glucoside. To check this point, the sugar derived from the metabolite by $\mathrm{HCl}$ hydrolysis was identified by cellulose TLC. As shown in Table 3, the $R_{f}$ values of the sugar corresponded to those of glucose in two solvent systems. The glucose content of the $\mathrm{HCl}$ hydrolysate of the metabolite was estimated by using glucose oxidase, and it was demonstrated that this compound constituted from D-glucose and riboflavin in a molar ratio of $1: 1$.

In order to examine the presence of a glucosidic bond and its configuration, the metabolite was digested with $\alpha$ - and $\beta$-glucosidases. The digestion with $\alpha$ - 
Table 2. $R_{f}$ values on silica gel TLC of the metabolite after various treatments.

\begin{tabular}{|c|c|c|c|c|}
\hline Treatment & Compound & I & II & III \\
\hline Photolysis in alkali & Metabolite & 0.42 & 0.58 & 0.48 \\
\hline \multirow[t]{2}{*}{$\mathrm{HCl}$} & Metabolite & 0.36 & 0.52 & 0.30 \\
\hline & Riboflavinyl glucoside & 0.36 & 0.52 & 0.30 \\
\hline \multirow[t]{2}{*}{$\alpha$-glucosidase } & Metabolite & 0.36 & 0.52 & 0.30 \\
\hline & Riboflavinyl glucoside & 0.36 & 0.52 & 0.30 \\
\hline \multirow[t]{4}{*}{$\beta$-glucosidase } & Metabolite & 0.23 & 0.40 & 0.12 \\
\hline & & $0.36^{\mathrm{a}}$ & $0.52^{\mathrm{a}}$ & $0.30^{\mathrm{a}}$ \\
\hline & Riboflavinyl glucoside & 0.23 & 0.40 & 0.12 \\
\hline & & $0.36^{\mathrm{a}}$ & $0.52^{\mathrm{a}}$ & $0.30^{\mathrm{a}}$ \\
\hline \multirow{4}{*}{$\begin{array}{c}\text { Oxidation with } \\
\text { periodic acid }\end{array}$} & & & & \\
\hline & Metabolite & 0.67 & 0.78 & 0.73 \\
\hline & Riboflavin & 0.67 & 0.78 & 0.73 \\
\hline & Riboflavinyl glucoside & 0.67 & 0.78 & 0.73 \\
\hline
\end{tabular}

Reaction conditions are described in MATERIALS AND METHODS. The concentration of the metabolite: 0.534 absorbance at $450 \mathrm{~nm}$. Reaction products were detected by their yellow fluorescence with excitation at $365 \mathrm{~nm}$. ${ }^{\text {a }}$ Trace amount was detected. Solvent systems: I, $n$-butanol-glacial acetic acid-water ( $4: 1: 5$, v/v, upper phase); II, benzene- $n$ butanol-methanol-water $(1: 2: 1: 1, \mathrm{v} / \mathrm{v}$, upper phase); III, methyl ethyl ketone-isoamyl alcohol-glacial acetic acid-water $(40: 40: 7: 13, \mathrm{v} / \mathrm{v})$.

Table 3. $R_{f}$ values on cellulose TLC of sugar part of the metabolite obtained by $\mathrm{HCl}$ hydrolysis.

\begin{tabular}{lcc}
\hline \multicolumn{1}{c}{ Sugar } & I & II \\
\hline From metabolite & 0.44 & 0.40 \\
From riboflavinyl glucoside & 0.44 & 0.40 \\
Glucose & 0.44 & 0.40 \\
Galactose & 0.38 & 0.45 \\
\hline
\end{tabular}

Sugars were detected with ammoniacal silver nitrate. Solvent systems: I, ethyl acetatepyridine-glacial acetic acid-water $(5: 5: 1: 3, \mathrm{v} / \mathrm{v}) ; \mathrm{II}$, phenol- $1 \%$ ammonia $(2: 1, \mathrm{v} / \mathrm{v})$.

glucosidase liberated riboflavin from the metabolite, but that with $\beta$-glucosidase scarcely liberated riboflavin (Table 2). Therefore, these results show that the riboflavin moiety would be linked to glucose through an $\alpha$-glucosidic bond.

The position of the glucosidic bond in the ribityl chain was examined by the reaction with periodic acid. The reaction product of the metabolite was compared with those of riboflavin and riboflavinyl glucoside by silica gel TLC. As shown in Table 2, the products from the metabolite, riboflavin and riboflavinyl glucoside 
gave the same $R_{f}$ value in the three solvent systems. Since it is known that the oxidation of riboflavin with periodic acid yields formylmethyl flavin(6), it is obvious that the product from the metabolite is formylmethyl flavin. Thus the $2^{\prime}$ and 3'-hydroxy groups could not be substituted by D-glucose, and that the glucosidic bond should exist at either the $4^{\prime}$ - or 5'-position.

From these results, we concluded that the metabolite is riboflavinyl glucoside which was first discovered by Whitby (7).

\section{Amount of riboflavinyl glucoside in rat urine}

The urine was collected for $24 \mathrm{~h}$ after oral administration of $4.684 \times 10^{6} \mathrm{dpm}$ $(37.3 \mu \mathrm{g})$ of $\left[2-{ }^{14} \mathrm{C}\right]$ riboflavin per rat. Total radioactivity and amount of riboflavin excreted in the urine were $889.5 \pm 108.3 \times 10^{3} \mathrm{dpm}$ and $82.2 \pm 13.1 \mu \mathrm{g}(n=4)$. Recovery of radioactivity in the urine was approximately $20 \%$ of the administered one. The radioactivity of riboflavinyl glucoside was estimated to be about $6 \%$ of the total radioactivity in the urine (Table 4).

Table 4. Urinary excretion of ${ }^{14} \mathrm{C}$-labeled metabolites during $24 \mathrm{~h}$ after oral administration of $\left[2-{ }^{14} \mathrm{C}\right]$ riboflavin to a rat.

\begin{tabular}{lc}
\hline \multicolumn{1}{c}{ Compound } & Per cent of radioactivity \\
\hline Riboflavinyl glucoside & $5.7 \pm 1.3$ \\
Riboflavin & $30.5 \pm 7.7$ \\
Chloroform-soluble compounds & $0.5 \pm 0.04$ \\
Sum of 7- and 8-carboxy lumichrome & $46.0 \pm 8.6$ \\
Unknown & $17.0 \pm 2.7$ \\
\hline
\end{tabular}

$\operatorname{Mean} \pm \operatorname{SE}(n=4)$

\section{DISCUSSION}

Among radioactive metabolites excreted into rat urine after oral administration of $\left[2-{ }^{14} \mathrm{C}\right]$ riboflavin, riboflavinyl $\alpha$-D-glucoside was demonstrated in the present study. Since this compound has been found by Whitby by reacting riboflavin with rat liver enzyme (7), it is conceivable that this metabolite is produced in rat liver and excreted into the urine. Taking into consideration the occurrence of the enzyme responsible for the formation of riboflavinyl glucoside in rat liver(3) and pig liver (8), this view becomes more reliable. This would be further supported by the finding of Kasai et al.(9) who demonstrated this compound in cat liver. On the other hand, there is also a possibility that riboflavinyl glucoside is a microbial product and is absorbed through the intestine and excreted into the urine. This possibility cannot be excluded and some part of this compound in the urine might originate from the product of the intestinal flora. Even so, it cannot deny the possible role of the liver, since we could detect qualitatively this compound in the 
urine of germ-free rat (details will apear elsewhere).

Although Katagiri et al. (10) reported photochemical formation of riboflavinyl glucoside, this possibility would be excluded in this case, because essentially the same results could be obtained by the experiments made in the dark room, and this compound was found to be not formed by the incubation of rat urine with [2${ }^{14} \mathrm{C}$ ]riboflavin for $24 \mathrm{~h}$ at room temperature in the dark.

In the present study, it becomes clear that after oral administration of radioactive riboflavin to a rat, three metabolites, 7- and 8-carboxy lumichrome and riboflavinyl glucoside, amount to a half of the total radioactivity excreted into the urine.

\section{REFERENCES}

1) Ohkawa, H., Ohishi, N., and Yagi, K. (1983): New metabolites of riboflavin appeared in rat urine. Biochem. Int., 6, 239-247.

2) Yagi, K., and Ohishi, N. (1971): Separating determination of flavins using thin layer chromatography. J. Vitaminol., 17, 49-51.

3) Whitby, L. G. (1952): Riboflavinyl glucoside: a new derivative of riboflavin. Biochem. J., 50, 433-438.

4) Yagi, K. (1956): Simplified lumiflavin method for the micro-determination of flavin compounds in animal tissues. J. Biochem., 43, 635-644.

5) Yagi, K. (1971): Simultaneous microdetermination of riboflavin, FMN and FAD in animal tissues, in Methods in Enzymology, ed. by McCormick, D. B., and Wright, L. D., Academic Press, New York, Vol. 18B, pp. 290-296.

6) Fall, H. H., and Petering, H. G. (1956): Metabolic inhibitors. I. 6,7-Dimethyl-9-formyl methyl isoalloxazine, 6,7-dimethyl-9-(2-hydroxyethyl) isoalloxazine and derivatives. $J$. Am. Chem. Soc., 78, 377-380.

7) Whitby, L. G. (1950): Enzymic formation of a new riboflavin derivative. Nature, 166, 479-480.

8) Uchida, K., and Suzuki, Y. (1974): Purification and properties of riboflavin $\alpha$-glucosidesynthesizing enzyme ( $\alpha$-glucosidase) from pig liver. Agric. Biol. Chem., 38, 195-206.

9) Kasai, S., Isemura, S., Masuoka, M., and Matsui, K. (1972): Identification of riboflavinyl $\alpha$-D-glucoside in cat liver. J. Vitaminol., 18, 17-23.

10) Katagiri, H., Yamada, H., and Imai, K. (1960): Transglycosidation relating to riboflavin by Escherichia coli. VIII. Photochemical glycosidation of riboflavin. $J$. Vitaminol., 6, 98-102. 